\title{
THE VALUE OF A TELEMETRY MONITORING SYSTEM IN SUSTAINING THE OPERATIONAL PERFORMANCE OF INDUSTRIAL INFORMATION SYSTEMS
}

\author{
J. Prinsloo ${ }^{1 * \#}$, M.J. Mathews ${ }^{1 \dagger}$ \& J.C. Vosloo ${ }^{1}$
}

\section{ARTICLE INFO}

\section{Article details}

Submitted by authors

4 Jul 2019

Accepted for publication 18 Jun 2020

Available online $\quad 31$ Aug 2020

\section{Contact details}

* Corresponding author jprinsloo@researchtoolbox.com

Author affiliations

1 Centre for Research and Continued Engineering Development (CRCED), North-West University, Pretoria, South Africa

\# $\quad$ Author was enrolled for a PhD at the North-West University's Centre for Research and Continued Engineering Development (CRCED) in Pretoria, South Africa

$\dagger \quad$ Author was a post-doctoral student at the North-West University's Centre for Research and Continued Engineering Development (CRCED) in Pretoria, South Africa

DOI

http: / /dx.doi.org/10.7166/31-2-2200

\section{ABSTRACT}

Revolutionary advances in the information and communication technology field pave the way for automation and data exchange in the heavy industry sector. Currently, Industry 4.0 solutions are more readily accepted in factories and in more advanced economies, where good infrastructure is in place to facilitate these solutions. In the context of these heavy industries, wide-area wireless telemetry networks play an important role in facilitating accessibility and allowing for real-time monitoring and data transmission over wide geographical distances. This paper emphasises the value of a new wireless telemetry monitoring and diagnostic system that allows for the development of a detailed troubleshooting methodology when communication disruptions occur. The system was implemented on an existing telemetry system that is used by an energy services company to maintain the operational status of various remote information systems. The network is also used to facilitate various demand-side management projects throughout the Republic of South Africa. The results obtained show that the proposed system can enhance the robustness of existing Industrial Internet of Things infrastructure, and this promotes the adoption of Industry 4.0 concepts in the heavy industry sector.

\section{OPSOMMING}

Revolusionêre vooruitgang in die inligting- en kommunikasietegnologieveld baan die weg vir outomatisering en data-uitruil in die swaar nywerheidsektor. Tans word oplossings van Industrie 4.0 makliker in fabrieke en in meer gevorderde ekonomieë aanvaar waar goeie infrastruktuur in plek is om hierdie oplossings te fasiliteer. In die konteks van hierdie swaar nywerhede speel wye draadlose telemetrie netwerke 'n belangrike rol om toeganklikheid te vergemaklik en vir intydse monitering en data-oordrag oor wye geografiese afstande voorsiening te maak. Hierdie manuskrip beklemtoon die waarde van 'n nuwe draadlose telemetrie monitering en diagnostiese stelsel om toe te laat dat ' $n$ gedetailleerde probleemoplossingsmetodologie ontwikkel word wanneer kommunikasieversteurings plaasvind. Die stelsel is geïmplementeer op 'n bestaande telemetrie stelsel wat gebruik word om die operasionele status van verskeie afgeleë inligtingstelsels te handhaaf. Die resultate het getoon dat die voorgestelde stelsel die robuustheid van bestaande 'Industrial Internet of Things'-infrastruktuur kan verbeter, en dit bevorder die aanvaarding van Industrie 4.0 konsepte in die swaar nywerheidsektor.

\section{INTRODUCTION}

Revolutionary advances in the information and communication technology field pave the way for automation and data exchange in the heavy industry sector [1]. The application of these Industry 4.0 technologies and methods can lead to the creation of 'smart' industries, which can improve production efficiencies, reduce production costs, and maintain reliable service delivery initiatives. Industry 4.0 solutions are currently more readily accepted in factories and in more advanced economies, where good infrastructure is in place to facilitate these solutions [2]. However, the adoption of these same techniques 
and solutions is slow in the heavy industries of developing economies, where infrastructure is poor and there are wide geographical distances between operating plants [3-6].

The backbone of Industry 4.0 techniques and solutions relies on machine-to-machine communication and wireless networks [7, 8], and therefore the quality and stability of the network layer forms a crucial part of an optimal Industry 4.0 ecosystem. Disruptions in accessibility and connectivity can thus effectively nullify the advantages of an Industry 4.0 ecosystem [2, 9-11].

In the context of these heavy industries, wide-area wireless telemetry networks play an important role in facilitating accessibility and allowing for real-time monitoring and data transmission over wide geographical distances [12-14]. It is infeasible to make use of traditional wired methods of communication due to the large geographical separation between industrial facilities. To achieve data transfer between remote locations, existing infrastructure, such as third party mobile cellular networks, is used [15-18].

The use of existing third party infrastructure implies that no control can be exercised over the network. The end user of the network must, therefore, cater for potential communication disruptions over which they have no control. Disruptions in communication can result in data loss, which can have a negative impact on the performance of industrial processes and systems. Several industrial information systems investigated in the literature rely heavily on a stable communication network [14, 19-21]. Should the existing cellular communication network experience disruptions in communications, these systems would become unreliable and have no benefit for industrial clients.

With industry currently using existing infrastructure such as cellular communication networks to carry out real-time communication and data transmission, there is a need for a telemetry monitoring system that actively monitors the status of the third party communication network. Since no control can be exercised over the network, quality-of-service issues cannot be directly addressed, and so a solution is required to enable corrective action to be taken.

\section{STATE OF THE ART}

From the start of the Internet of Things (IOT) revolution, cellular communication technologies and infrastructure played a dominant role in facilitating real-time communication [22]. To use this infrastructure for real-time data transmission, minimal hardware needs to be installed. For most applications, a single industrial router is required, after which access can be obtained to the entire cellular network. In addition to the installation of a router, mobile subscriber identification modules (SIMs) must be incorporated to allow for wireless communication [17].

Mobile communication networks have been a key enabler of various loT applications [23-26]. These networks consist of technical characteristics that allow effective communication to take place. The critical parameters listed below have been identified from the literature as key components that can cause communication disruptions if not managed and monitored properly [27]:

- $\quad$ Overall network quality, measured by packet transmissions [28];

- $\quad$ mobile network bandwidth; and

- mobile network signal strength and attenuation.

It is possible to access these characteristics via the industrial router, since integrated hardware allows these characteristics to be measured. With network characteristic data available, a system can be developed that extracts the parameter values of the different characteristics from the industrial router.

Several network monitoring systems have been proposed in the literature. A system that can monitor the performance of wireless networks of a heterogeneous nature in the context of local smart factories is proposed by Gisbert et al. [29]. The ability to reconfigure wireless communication nodes based on the quality of the network is one of the key features of this system. The objective of the proposed system is to help guarantee the robustness and reliability of wireless communications in the context of local dynamic smart factories. This system does not, however, address the limitations present in wide-area wireless communications, and no troubleshooting methodology has been presented to troubleshoot network problems.

Civerchia et al. [30] proposed a localised Industrial Internet of Things monitoring system for predictive maintenance applications. The main objective of the system is to facilitate pervasive monitoring of 
industrial machinery. This allows for predictive maintenance applications and strategies to be implemented. Although this system successfully achieved real-time monitoring of industrial equipment, it should be noted that emphasis was placed on the monitoring of industrial equipment, and not on the communication network that facilitates data transfer. Second, the system was implemented in a localised environment where sensor nodes could be easily installed and monitored. When industrial plants are separated by wide geographical distances, the quality and reliability of wide-area wireless telemetry becomes a concern; and this system does not address the challenges present in wide-area wireless communication [31].

Prinsloo, Mathews, du Plessis and Vosloo [32] developed a monitoring and information system to assist with real-time communication anomalies in industrial telemetry applications. This system focuses primarily on wide-area wireless telemetry systems that make use of the cellular network to achieve real-time data transmission. The objective is to monitor the connection uplink of Global System for Mobile Communicationbased telemetry systems with the aim of improving service delivery in the South African heavy industry sector. Although this system succeeded in detecting communication anomalies, various critical network parameters have been neglected in the system design. The system only focuses on the communication uplink, and does not consider network parameters such as cellular network bandwith and signal strength. Both of these parameters can have a direct impact on the quality and reliability of wide-area wireless telemetry networks. This paper therefore aims to expand this system by introducing the monitoring of these parameters.

Various methods and techniques for monitoring communication networks have been proposed. One method of monitoring the status and quality of a communication network is to make use of active probing routines. For active probing, the user injects packets into the network from a host, and observes the response from the network to the injected packets. Active probing is the primary method for monitoring the status of a network [28]. Communication protocols, such as transmission control protocol (TCP) and internet control message protocol (ICMP), are regarded as the predominant protocols to implement active probing on a network [33-35].

Intermittent connectivity in mobile communication networks can have the effect of hampering the quality of service (QoS), and thus the effectiveness of information systems in the heavy industry sector [36-38]. Industrial information systems will fall short of their objectives if no input data is received from industrial sites. The existing network infrastructure used for real-time data transmission is therefore considered to be a critical component in the overall information system architecture, as well as in other loT-related systems [39-40].

An external monitoring system is therefore required that provides insight into the status of third party networks. By gaining insight into the status of the cellular network, a detailed troubleshooting methodology can be developed and used in the event of communication disruptions. The aim of this paper is thus to illustrate the value of such a system in the context of industrial communication.

\section{METHODOLOGY}

The effectiveness of information systems and other Industry 4.0-related applications can be severely limited if no stable communication network is present. This paper emphasises the value of a new wireless telemetry monitoring and diagnostic system that allows for the development of a detailed troubleshooting methodology when communication disruptions occur. The system was implemented on an existing telemetry system that is used to maintain the operational status of various remote information systems.

\subsection{System architecture}

The telemetry monitoring system consists of three main design components, which are presented and discussed below.

1. Component 1 - The physical layer: The first component of the system focuses on the acquisition of data. To determine the state of the communication network, data needs to be retrieved. This is done by using an active probing procedure to determine whether the communication network is online. For the proposed system, the physical layer will be the execution of active probing software routines to determine the state of the various network parameters listed in Table 1 below.

2. Component 2 - The data layer: The results obtained from the active probing routine then need to be processed and stored in a database. This component is categorised as the data layer of the system. Active probing procedures are invoked routinely during the day, and the data is processed to obtain 
daily and hourly averages. The data layer also acts as a historian that can be used as an additional tool to evaluate the performance of energy management systems. For the proposed system, the data layer will be in the form of an SQL database.

3. Component 3 - The application layer: The final component of the system allows the processed data to be relayed to visual dashboards for analysis and decision-making purposes. The application layer allows trained personnel to start a troubleshooting and diagnostic process to rectify issues that might arise without the need to travel to the actual industrial site to start troubleshooting. For the proposed system, the application layer will be in the form of a graphical user interface (GUI).

A modular design approach has been followed to allow for rapid expansion if additional industrial sites need to be included for telemetry monitoring purposes. Visual dashboards are presented to personnel, and serve as a graphical user interface on which telemetry status signals can be viewed.

\subsection{Physical layer}

Industrial plants and compounds are distributed across large geographical distances. To enable data transmission, the mobile cellular communication network is used as the communication infrastructure. This requires industrial mobile cellular communication routers to be installed on-site to facilitate data transmission via the cellular network. For mobile cellular communication routers to transmit data successfully, SIMs must be present in every router.

In several cases, industrial facilities serve as a hub for wireless data transmission. Data is transmitted from other facilities to one central location, from which control systems can acquire access to the data via an open platform communication interface. Mobile cellular communication routers are also used for this purpose. Internet protocol (IP) addresses are assigned to all remote end-points, which are also interconnected via a virtual private network (VPN). Figure 1 below shows the scope of wide-area wireless communication, as well as the strategic importance of the proposed system.

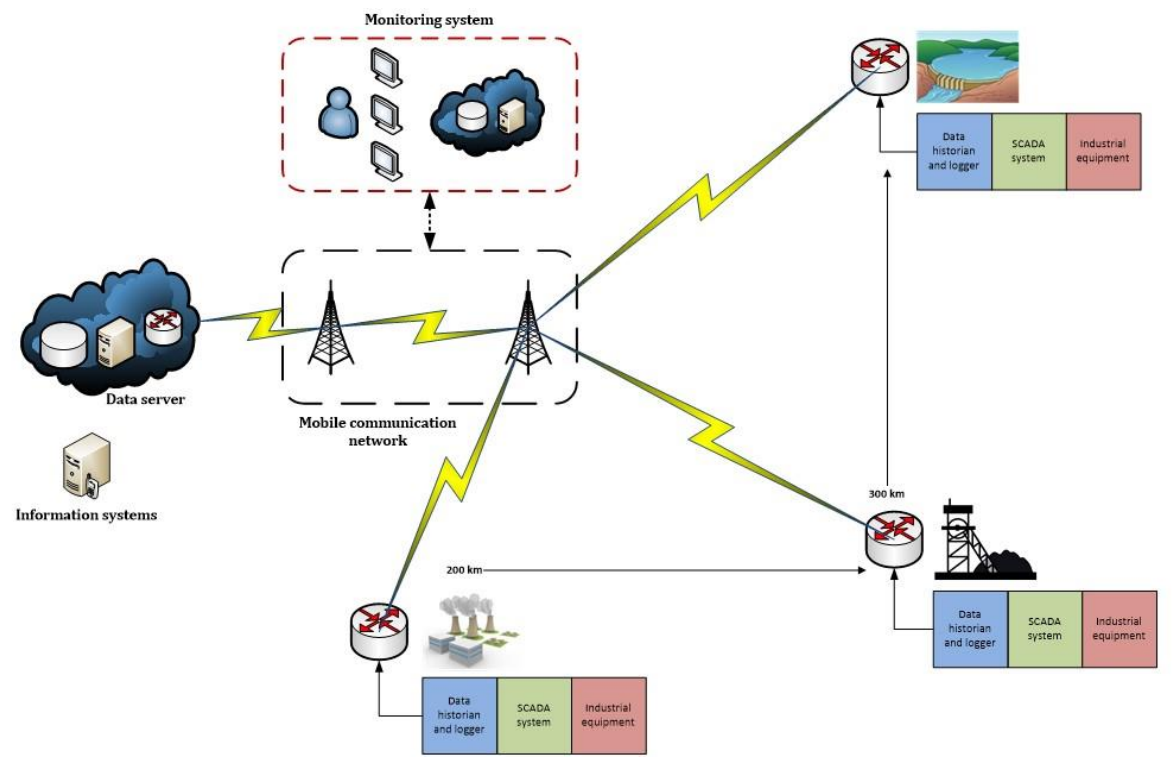

Figure 1: The scope of the proposed telemetry monitoring system in an existing IloT energy management ecosystem

\subsection{Data layer}

Three key perspectives that are crucial to the overall quality and stability of a wireless communication network were identified from the literature. The first perspective is the global operational status of the wireless communication network. This perspective can be labelled the 'line-of-site' perspective, even though wide-area wireless communications are not considered to be directional.

Active probing methods are regarded as the best approach to determine the state of a network [28]. Software subroutines were implemented to determine the operational status of the line-of-site perspective. This entails the transmission of data packets across the network link to the receiving endpoint located at an industrial facility. An operational end-point with a stable link will reply with an echo data packet in 
response to the active probing transmission. The responses can then be recorded, and a history can be compiled for troubleshooting purposes.

The second perspective focuses on the use of mobile data to facilitate all network communication. Mobile data is an expensive resource, and so it should be constantly monitored. A depletion in the mobile data bundle will also result in network downtime, which is unacceptable in the context of Industry 4.0 applications.

The third and final perspective focuses on the quality of the network link. This can be determined by looking at the signal strength of the network, as signal strength provides valuable insight into the current state of the network, and can highlight potential issues such as coverage gaps in remote areas, as well as interference that might disrupt wireless communication over long distances. Figure 2 below illustrates the operation of the system.

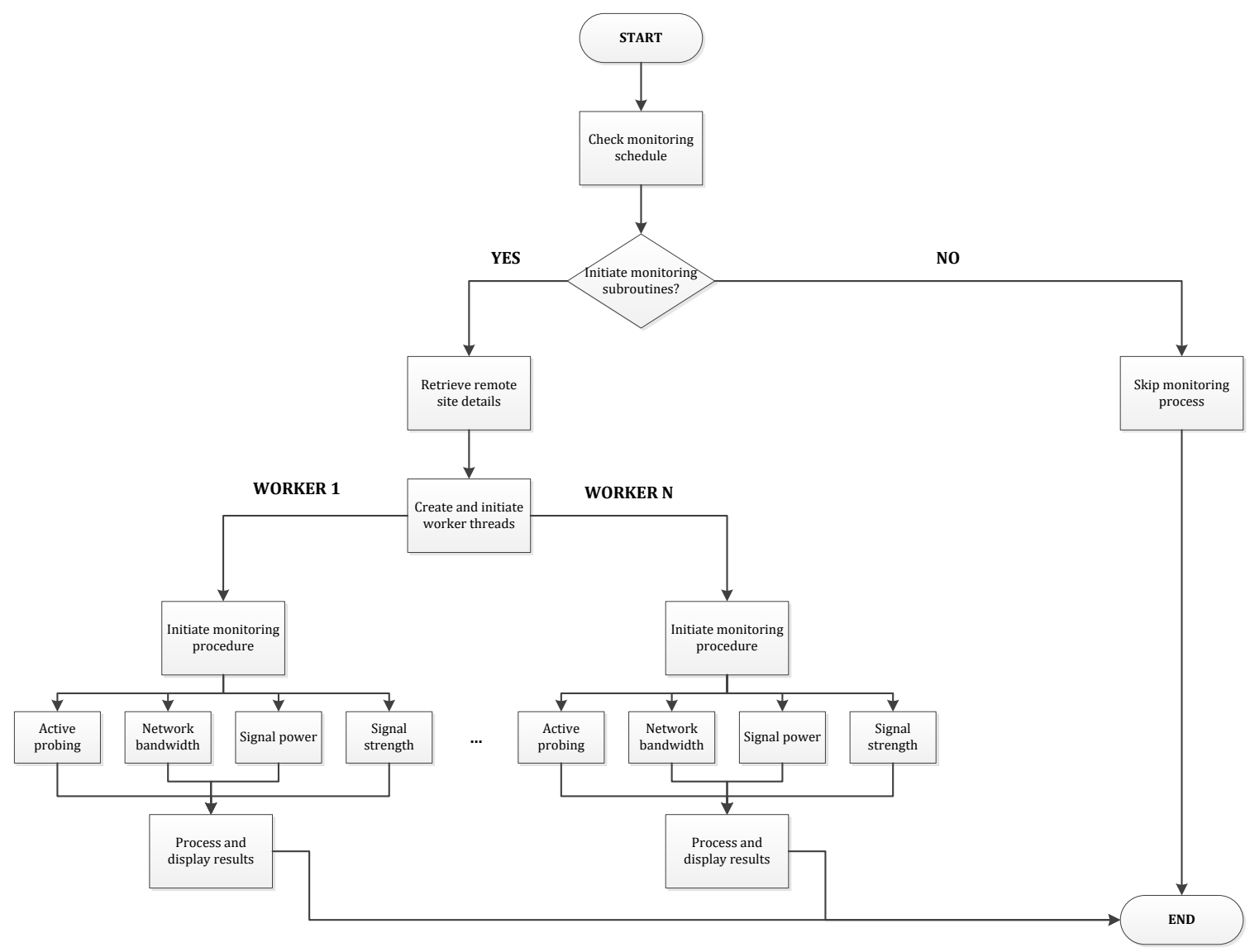

Figure 2: A detailed software architectural flow of the telemetry monitoring system

The two main techniques for network monitoring are active probing and passive probing. During system implementation, it was decided to make use of active probing procedures. These involve the transmission of internet control message protocol (ICMP) packets across the network to the remote industrial end-point. The resulting response from the remote end-point is then used to determine the state of the remote endpoint. All remote IP addresses are retrieved from the database and stored in a data structure. Worker threads are then created, with each worker thread responsible for checking the connection status of a single IP address. By using active probing, all active remote end-points will reply. The resulting replies are then stored in the database for processing and display purposes.

To optimise the performance of the monitoring system, multithreading techniques have been employed for all software routines. All active probing routines, as well as database operations, are thus executed in a multithreading environment. This allows for effective monitoring of remote end-points, regardless of the number of end-points that need to be monitored. The active probing software routine is executed 
periodically in real time. The use of a multithreading environment allows for any number of sites to be monitored, which implies that the system is easily expandable if required.

The proposed system allows for the monitoring of several key mobile cellular communication network parameters. The monitoring of key network parameters also introduces several capabilities that assist maintenance personnel in troubleshooting. These network parameters, as well as the capabilities, are listed and discussed in Table 1 below.

Table 1: Monitoring system objectives and capabilities

\begin{tabular}{|c|c|c|}
\hline $\begin{array}{c}\text { Network } \\
\text { parameter }\end{array}$ & Monitoring objective & Maintenance capabilities \\
\hline $\begin{array}{l}\text { Active } \\
\text { probing } \\
\text { success rate }\end{array}$ & $\begin{array}{l}\text { The objective of active probing success rate } \\
\text { monitoring is to determine the overall quality of } \\
\text { the telemetry uplink. ICMP packets are } \\
\text { transmitted across the network, and replies from } \\
\text { remote end-points are logged. An average success } \\
\text { rate based on the number of successful replies is } \\
\text { calculated and stored as a percentage value. } \\
\text { Section } 4.1 \text { provides results from two case studies. }\end{array}$ & $\begin{array}{l}\text { The active probing success rate serves as the } \\
\text { primary indicator of the status of the network } \\
\text { uplink for a remote end-point. Maintenance } \\
\text { personnel can use this parameter to } \\
\text { determine the overall quality of the } \\
\text { communication network. }\end{array}$ \\
\hline $\begin{array}{l}\text { Network } \\
\text { bandwidth }\end{array}$ & $\begin{array}{l}\text { The objective of network bandwidth monitoring is } \\
\text { to determine the available bandwidth for each } \\
\text { individual end-point. In most cases, wireless data } \\
\text { transmission will cease if bandwidth levels drop to } \\
\text { zero. For national key points, data transmission } \\
\text { will continue, but the cost of communication will } \\
\text { increase significantly due to 'out of bundle' data } \\
\text { rates. Section } 4.2 \text { provides results from two case } \\
\text { studies. }\end{array}$ & $\begin{array}{l}\text { Monitoring of network bandwidth allows } \\
\text { maintenance personnel to determine the } \\
\text { transmission load of individual end-points. } \\
\text { Industrial sites that continuously transmit } \\
\text { large amounts of data will deplete their } \\
\text { bandwidth levels at a much faster rate. This } \\
\text { parameter allows maintenance personnel to } \\
\text { check wireless data transmission from a site } \\
\text { proactively. }\end{array}$ \\
\hline $\begin{array}{l}\text { Signal } \\
\text { power }\end{array}$ & $\begin{array}{l}\text { The objective of signal power monitoring is to } \\
\text { determine the signal power level for each } \\
\text { individual end-point. The signal power level is } \\
\text { measured in decibel-milliwatts }(\mathrm{dBm}) \text {. The signal } \\
\text { power level provides an accurate representation of } \\
\text { the absolute power levels of the network end- } \\
\text { point. The signal power can also be defined as a } \\
\text { received signal strength indicator (RSSI). }\end{array}$ & See ‘Network signal’ below. \\
\hline $\begin{array}{l}\text { Network } \\
\text { signal }\end{array}$ & $\begin{array}{l}\text { The signal power level is used to provide } \\
\text { maintenance personnel with a colourised } \\
\text { representation of the router signal strength. The } \\
\text { network signal parameter is converted to a } \\
\text { percentage value from the RSSI indicator. Section } \\
4.3 \text { provides results from a case study. }\end{array}$ & $\begin{array}{l}\text { The colourised representation of the RSSI } \\
\text { value discussed above gives maintenance } \\
\text { personnel a visual representation of the } \\
\text { current network signal strength. Poor network } \\
\text { signal strength should encourage maintenance } \\
\text { personnel to investigate external factors, such } \\
\text { as radio frequency interference. }\end{array}$ \\
\hline
\end{tabular}

\subsection{Application layer}

By gaining insight into the status of the cellular network, a detailed troubleshooting methodology can be developed and used in the event of communication disruptions. Holistically, three overarching challenges are present that disrupt wide-area wireless communications: network challenges, network billing issues, and equipment challenges.

In all three challenges, data transmission from sites will fail. This implies that information gaps will be present on industrial information systems that rely on wide-area wireless communication for data transmission for each of the three disruption cases mentioned above. A detailed troubleshooting methodology is therefore needed to determine the exact cause of any information gap in industrial information systems. The system described in this paper addresses this need, and allows for effective troubleshooting to take place in the context of wide-area wireless communications for industrial players.

Table 2 below gives a summary of the different communication disruption scenarios that can be present, and graphically illustrates how the system will represent the disruption. The scenario is then mapped to a potential root cause of the disruption. A troubleshooting procedure is then presented, which must be followed to resolve the communication disruption. Several case studies, which serve to emphasise the importance of gaining insight into the status of the cellular network for industrial data transmission purposes, are presented in Section 4. Each illustration contains an area chart and a line chart. The area 
chart represents a specific network measurement, while the line chart represents an equipment measurement. Implementing the proposed system allows for a detailed mapping of any communication anomaly to determine the root cause of communication disruptions.

\section{Table 2: Communication disruption diagnosis and troubleshooting}

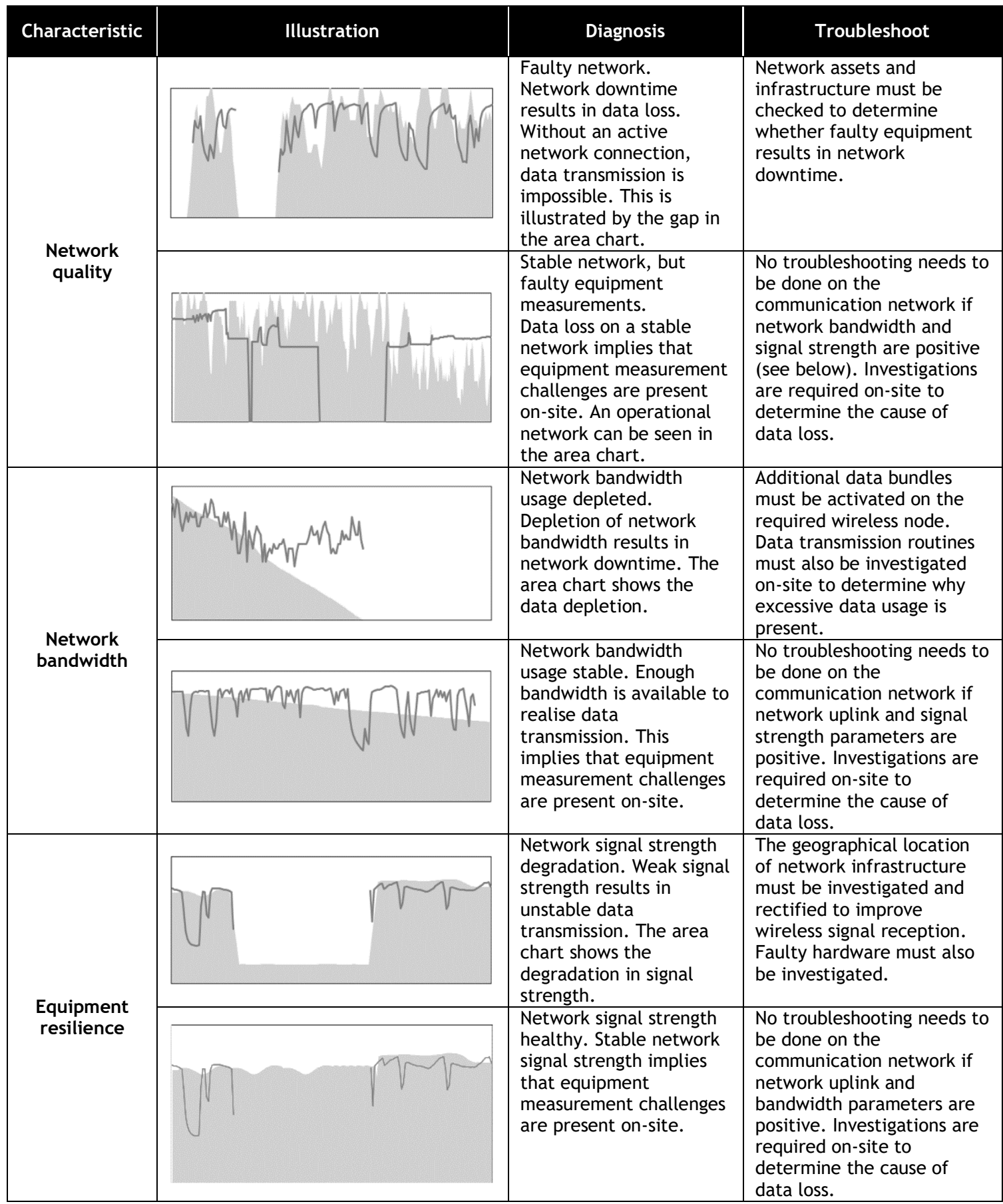

\subsection{System application and verification}

The developed system was implemented on an existing telemetry network that is used by an energy services company to facilitate various demand-side management projects throughout the Republic of South Africa. About 80 remote industrial sites are currently within the scope of the telemetry monitoring system, which implies that the system has a direct impact on the performance of thousands of individual items of industrial 
equipment. The energy services company uses multiple mobile cellular communication networks to facilitate real-time data transmission across remote industrial locations. The system that is being monitored consists of a collection of industrial cellular routers designed by Truteq.

The energy services company currently maintains demand-side management projects that are distributed in seven of the nine national provinces. Wide-area wireless communications are used to facilitate real-time data transfer and remote troubleshooting. In addition to the active demand-side management projects, the energy services company also maintains condition-based maintenance agreements with multiple industrial energy consumers.

Results from the developed system are detailed and discussed in Section 4 below. The results from the telemetry monitoring system are represented by area graphs with the scale on the right $y$-axis, while the results from the industrial information system are displayed by line graphs with the scale on the left $y$-axis. All results are time-based, so the $\mathrm{x}$-axis is broken down into a time component.

\section{RESULTS}

This section presents various case studies to validate the impact of this system and to emphasise the value of the system in industry, which includes mining industries and various national key points such as water pumping schemes and power stations.

Three major real-world troubleshooting scenarios are presented to illustrate the troubleshooting procedure for root cause challenges. The first scenario focuses on the importance of constantly monitoring the status of line-of-sight communication to remote sites to determine the overall quality of the mobile network. The second scenario focuses on the monitoring of mobile network bandwidth, and the third scenario focuses on the monitoring of mobile network signal strength. The importance of these three parameters has been highlighted in the previous section.

All three mobile network characteristics are monitored by the proposed system, and are presented on the secondary vertical axis of each graph. A critical equipment measurement is represented on the primary vertical axis of each graph. Finally, all results are provided for a certain period, defined on the horizontal axis of each graph. It should be mentioned that the critical equipment measurement present in each graph represents a specific equipment characteristic, and can be viewed as correct for the purpose of this study.

\subsection{Perspective 1: Troubleshooting network uplink challenges}

Perspective 1 presents two case studies. These case studies aim to illustrate the value of the monitoring system on critical industrial systems that need constant monitoring. The first case study illustrates the effect of telemetry link downtime. The second case study illustrates how the telemetry monitoring system assisted maintenance personnel to conduct effective maintenance.

\subsubsection{Case study A: Network communication failure}

One key observation that needs to be made is the data loss that is present in Figure 3. Data loss occurred in two separate periods during which no accurate assessment could be made on the temperature levels of the pump unit. Scenarios like these require energy services companies (ESCos) to send out maintenance teams to investigate, troubleshoot, and restore system operation. This is a time-consuming task when the exact cause for data loss is not determined prior to arriving on site.

The status of the telemetry system between the ESCo and the industrial site on which the pump asset is situated is illustrated by the area chart in Figure 3. The graph shows the average active probing success rate of the telemetry uplink to the remote industrial site for the month during which data-loss was experienced. A clear drop in the communication uplink can be seen at two separate places. This resulted in a failure to relay real-time data to the information system. However, the communication link to the remote site was restored, which allowed for the successful transmission and reception of real-time pump temperature levels.

The telemetry system was successful in determining the cause of data loss. This aided the maintenance team greatly, since the number of factors that could lead to data loss was reduced to the communication network alone. After the rectification of the communication network downtime, real-time data transfer resumed. 


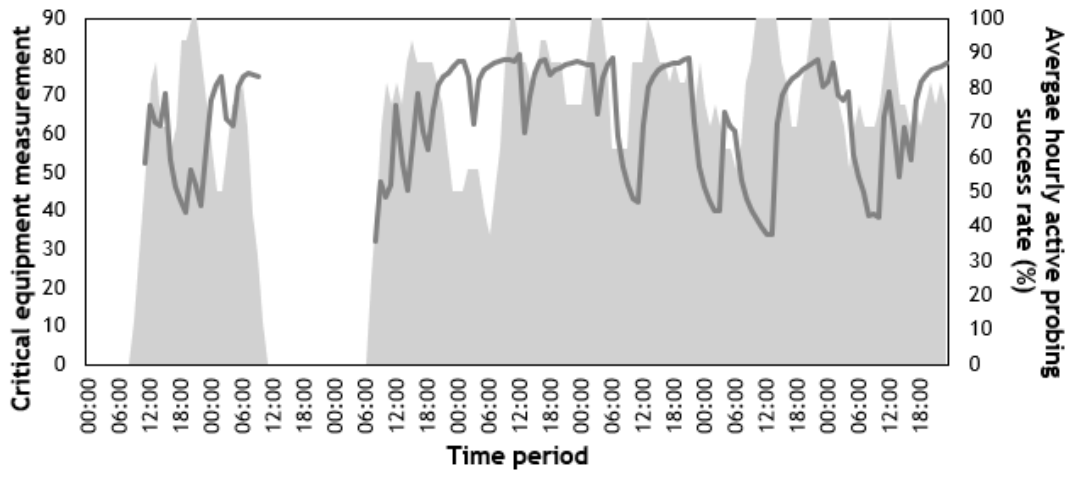

Telemetry network status _Equipment measurement

Figure 3: Chart that shows a critical equipment measurement, as well as the status of the telemetry system

\subsubsection{Case study B: Stable communication network}

Figure 4 shows a period when all temperature levels dropped to zero. This prompted an investigation to determine whether real-time data transmission from the site was operational or not. The monitoring data from the telemetry monitoring system indicated that real-time data transmission from the site was indeed active and operational. The status of the telemetry uplink between the ESCo and the remote industrial site is again illustrated by the area chart in Figure 4.

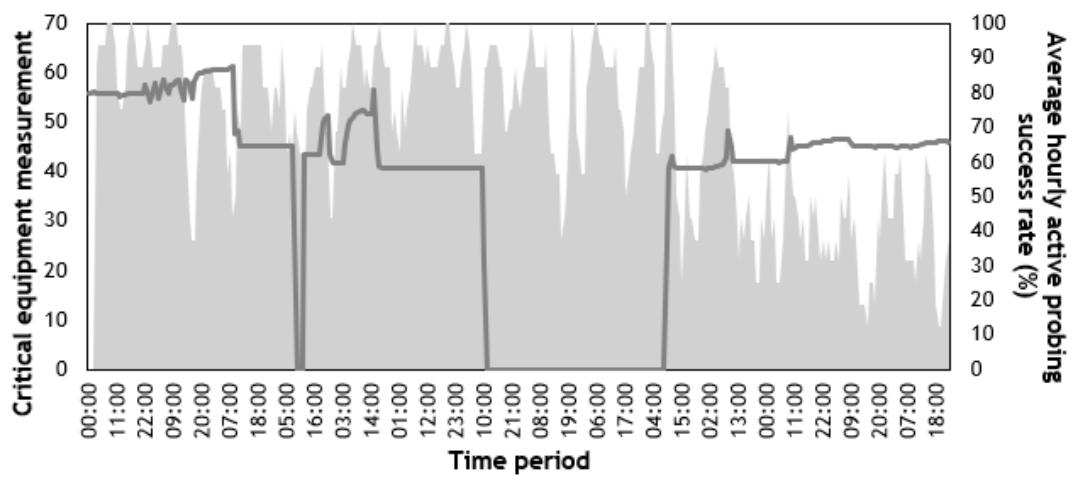

Telemetry network status _Equipment measurement

Figure 4: Chart that shows a critical equipment measurement

Since a stable communication uplink was present between the ESCo and the remote industrial site (represented by the area chart), it was possible to connect remotely to the energy management server on site. On connecting, it was established that the open platform communication (OPC) server was offline. The OPC server allows for direct communication between the on-site energy management system and the industrial supervisory control and data acquisition (SCADA) platform of the energy consumer. After the issue had been rectified, real-time temperature levels returned to normal operating levels.

One final observation is the decline in the quality of the telemetry network uplink in the final section of the graph. The network is stable enough to allow for remote maintenance to be conducted, as well as to facilitate successful transmission of efficiency parameters. However, the decline in the quality does signal that network downtime can be expected, and proactive measures should, therefore, be implemented to prevent any network downtime. The results illustrated in Figure 4, therefore, illustrate the proactive maintenance component that the system introduces into an existing IloT ecosystem. 


\subsection{Perspective 2: Troubleshooting network bandwidth usage}

Excessive data usage was reported on multiple systems that formed part of the maintenance agreements. The data usage is due to the volume of data transferred from the site to the information system. The telemetry monitoring system uses minimal data for network probing purposes. Two case studies are presented. The first case study illustrates a loss in component data, but with stable data usage. The second case study illustrates the effect of excessive data usage that resulted in a data limit being reached. Once the limit was reached, all communication to the site was lost and no data could be received. In the event of a data limit being reached, the mobile service provider requires the client to purchase additional data bundles to re-enable communication. This results in additional network costs and the operational downtime of industrial information systems.

\subsubsection{Case study C: Stable bandwidth usage}

Figure 5 below shows a clear discontinuity in the temperature data for the pump component. The hourly mobile data information obtained by the telemetry monitoring system showed that sufficient data was present to allow for real-time data transmission (represented by the area chart). This prompted an investigation into the cause of data loss, which was found to be system downtime. Unresponsive software was restarted, and a server reboot was required to resolve the issue. The telemetry monitoring system parameters, specifically the data level, indicated that the issue was located on-site.
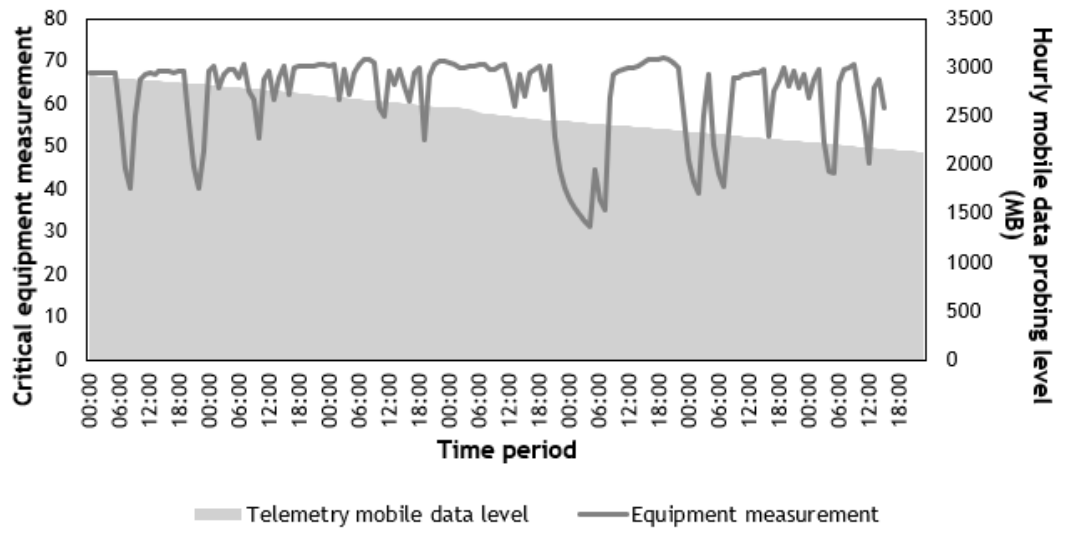

\section{Figure 5: Chart that shows a critical equipment measurement, as well as the status of the mobile data level}

After rectifying the issue, data transmission resumed. By monitoring the data level, additional insight was obtained into the status of the communication network. This, in turn, assisted with effective diagnostics and troubleshooting. Depletion of a data bundle results in communication downtime, as can be seen in the next case study.

\subsubsection{Case study D: Bandwidth depletion}

Data loss is once again present in Figure 6 (represented by the line chart). One key observation is that the actual data level of the communication network was depleted at a significant rate (represented by the area chart). Real-time data transmission and remote monitoring and maintenance procedures are impossible once a data bundle has been depleted. To rectify the issue, an additional data bundle must be manually loaded. Loading a data bundle can take several hours to reflect on the system, which results in a temporary dead time, during which no data transmission is possible. The telemetry monitoring system can proactively prevent dead times by constantly monitoring the data usage of a remote end-point.

Excessive data consumption has various causes. The first and most common cause for excessive consumption is negligence on the part of maintenance personnel. The communication uplink to sites is also used to allow for remote desktop sessions so that maintenance personnel can perform routine maintenance and inspections remotely. Remote desktop sessions are resource-intensive, and should only be executed on a fixed schedule or when the need arises. Failure to close a remote session is common; and this increases the load on the telemetry data bundle pool. Furthermore, several industrial sites serve as national key points, which means that connections are not allowed to be blocked. If bandwidth is depleted for a national key point, communication must be allowed to continue at out-of-bundle data rates, since a blocked connection would result in communication downtime. 


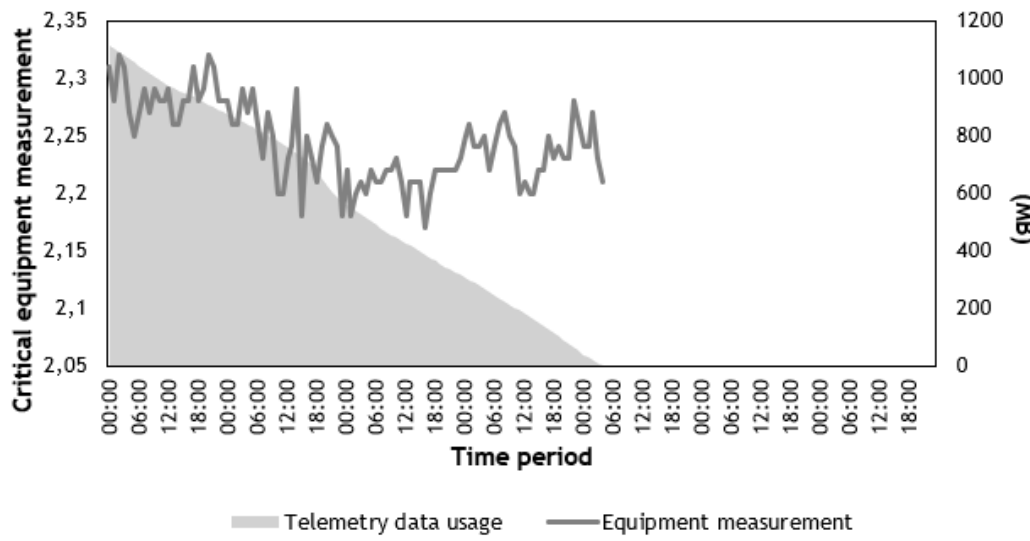

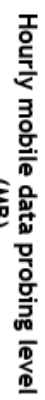

Figure 6: Chart that shows a critical equipment measurement, as well as the status of the mobile data level

A second cause of excessive data consumption is the continuous retransmission of raw data from the site, as well as the excessive manual transfer of raw data files. The manual transmission of raw data files must be kept to a minimum, as they are large. An email client is used to transmit raw data from site to the storage and processing facility. The continuous retransmission of data, or transmission looping, occurs when a dataset is retransmitted over the network, even when the previous transmission was successful. Retransmission should occur only when the previous data transmission has failed. Transmission looping usually occurs when the email client fails to delete on-site data from the transmission directory. Additional software abnormalities, such as irregular data logging on the data server itself, can also result in data retransmission.

The causes of excessive data consumption form part of the troubleshooting and diagnostics process of the dedicated maintenance teams. The telemetry monitoring system assists the maintenance team by providing a reference point from which troubleshooting can be done.

\subsection{Perspective 3: Troubleshooting network signal strength degradation}

Signal strength levels play a vital role in sustaining maintenance agreement effectiveness. One case study is presented below. It illustrates the effect of weak signal strength on the real-time monitoring capabilities for maintenance agreement purposes.

\subsubsection{Case study E: Network equipment failure}

Figure 7 shows a clear drop in the quality of the network signal strength (represented by the area chart). This drop results in data loss (represented by the line chart). A variety of factors, such as electromagnetic interference and limited network coverage, can influence the signal strength of wide-area wireless communications. To compensate for the gaps in network coverage, a detailed coverage investigation must first be done to determine the state of the network coverage. This information must then be used to determine a suitable location for the installation of an energy management system and the supporting infrastructure.

The decline in the signal strength shown in Figure 7 was a result of infrastructure being moved to a different on-site location. The new location experienced periodic dead times in network coverage, which resulted in occasional dead times during which no data transmission was possible. The telemetry monitoring system assisted with diagnostics and troubleshooting, and the issue was rectified by moving the installed infrastructure to a new position. 


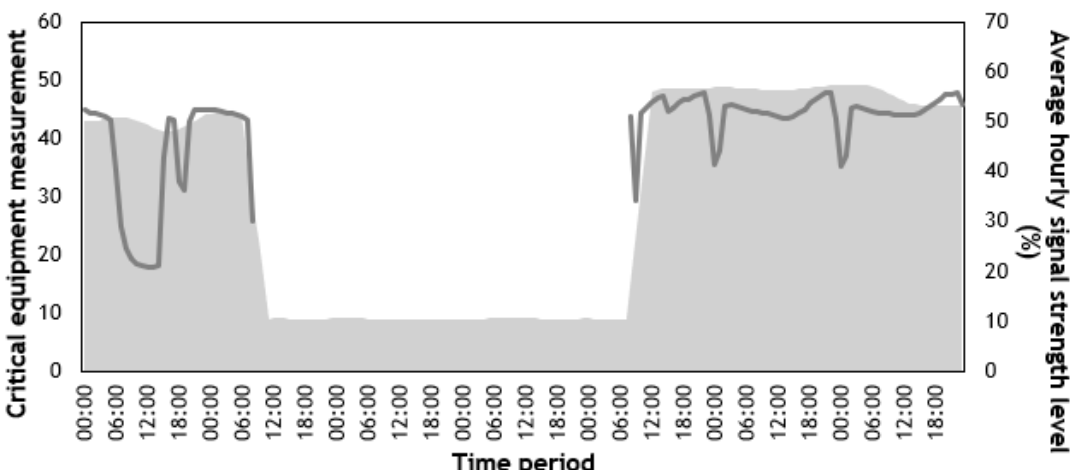

Telemetry signal strength _Equipment measurement

Figure 7: Chart that shows a critical equipment measurement, as well as the status of the telemetry signal strength

\section{DISCUSSION}

With industry still using the existing infrastructure to achieve real-time communication and data transmission via the cellular network, there was a need to develop a telemetry monitoring system that actively monitored the status of the communication network. Since the network could not be controlled, quality of service issues could not be directly addressed. An external monitoring system was therefore required that provided insight into the status of the cellular network. By doing so, a detailed troubleshooting methodology could be developed and used in the event of communication disruptions.

The telemetry monitoring system succeeded in providing accurate insight into the status of the mobile communication networks used by remote industrial sites, by monitoring overall network quality, network bandwidth, and network signal strength. However, there is scope for future work and improvements. The telemetry monitoring system is currently isolated from the existing energy management ecosystem. Although actual results are combined to give a more causal representation of information system data loss, the system is physically separated from other information systems. There is a need to combine the telemetry monitoring system with existing information systems, such as energy management information systems and condition-based maintenance systems.

The inclusion of telemetry status parameters in reports that can then be sent to industrial consumers is also considered to be an appropriate expansion to the current solution. By including the results of the telemetry monitoring system in the automatic report generation structure, detailed insight can be obtained into the overall health of the energy management ecosystem. This will also promote information awareness and increase the ability to perform proactive maintenance.

Several existing systems in the literature have been presented and discussed in Section 1 of this paper [13$15,19,21]$. The review of existing industrial information system applications in Section 2 showed that industrial information systems do not include monitoring routines for the status and quality of wide-area wireless telemetry networks. It is believed that the telemetry monitoring system proposed in this paper would greatly strengthen these systems.

The implementation of a telemetry monitoring system ensures that the full potential of industrial information systems can be achieved. By monitoring the status of the telemetry between an energy services company and remote industrial sites, the overall quality of service can be improved and sustained. The proposed system also implements a novel approach of combining telemetry monitoring data with industrial information system data. By doing so, accurate and effective troubleshooting can be done to determine the cause of potential data loss in industrial information systems.

Real-time data transmission, processingm and display are crucial factors in condition-based maintenance systems and energy management information systems. The proposed system ensures that these factors are maintained to ensure smooth operation. Effective maintenance strategies and the need-to-know are also 
considered to be crucial factors in energy savings initiatives. The proposed system could assist in this to maintain energy management system stability.

\section{6}

\section{CONCLUSION}

The performance of integrated demand-side management projects and other maintenance strategies can be greatly affected by an unstable telemetry uplink between an energy services company and a remote industrial site. An investigation into the state of the art of Industry 4.0 applications showed that Industrial loT applications rely on a stable telemetry uplink, but do not monitor the uplink itself. This implies that current IloT systems can be unreliable if the quality of the communication network degrades.

This paper emphasised the value of a stand-alone telemetry monitoring system that can independently monitor the status and quality of a mobile communication network. The proposed system was developed and implemented on the existing telemetry network of a South African energy services company. Around 80 sites, each with a fully functional energy management system on-site, were incorporated into the scope of the monitoring system. This allowed for more than a thousand individual industrial assets to be monitored and maintained.

The results demonstrate the value of this system. Positive impacts were made on equipment monitoring in the heavy industry sector. The system is generic and can, therefore, be applied to any lloT ecosystem where mobile communication networks are used for real-time data transmission. The results show that the proposed system can enhance the robustness of existing IloT infrastructure; and this promotes the adoption of Industry 4.0 concepts in the heavy industry sector.

\section{ACKNOWLEDGEMENTS}

This research did not receive any specific grant from funding agencies in the public, commercial, or notfor-profit sectors. The authors would like to express their gratitude to the reviewers for the suggestions they provided, which added value to the quality of this paper. This work is sponsored by ETA Operations (Pty) Ltd.

\section{REFERENCES}

[1] Sung, T. K. 2018. Industry 4.0: A Korea perspective. Technological Forecasting and Social Change, 132, pp. 40-45.

[2] Lu, Y. 2017. Industry 4.0: A survey on technologies, applications and open research issues. Journal of Industrial Information Integration, 6, pp. 1-10.

[3] Shrouf, F., Ordieres, J. \& Miragliotta, G. 2014. Smart factories in Industry 4.0: A review of the concept and of energy management approached in production based on the Internet of Things paradigm. 2014 IEEE International Conference on Industrial Engineering and Engineering Management, pp. 697-701.

[4] Zhang, F., Liu, M., Zhou, Z. \& Shen, W. 2016. An loT-based online monitoring system for continuous steel casting. IEEE Internet of Things Journal, 3(6), pp. 1355-1363.

[5] Sicari, S., Rizzardi, A., Miorandi, D., Cappiello, C. \& Coen-Porisini, A. 2016. A secure and quality-aware prototypical architecture for the Internet of Things. Information Systems, 58, pp. 43-55.

[6] Kim, W., Jeong, O.-R., Kim, C. \& So, J. 2011. The dark side of the Internet: Attacks, costs and responses. Information Systems, 36(3), pp. 675-705.

[7] Terblanche, G., Kleingeld, M. \& Joubert, R. 2017. A hands-on approach to managing industrial DSM projects. 2017 International Conference on the Industrial and Commercial Use of Energy (ICUE), pp. 1-6.

[8] Rizzardi, A., Sicari, S., Miorandi, D. \& Coen-Porisini, A. 2016. AUPS: An open source AUthenticated Publish/Subscribe system for the Internet of Things. Information Systems, 62, pp. 29-41.

[9] Huang, Z., Yu, H., Peng, Z. \& Feng, Y. 2017. Planning community energy system in the industry 4.0 era: Achievements, challenges and a potential solution. Renewable and Sustainable Energy Reviews, 78, pp. 710-721.

[10] Hofmann, E. \& Rüsch, M. 2017. Industry 4.0 and the current status as well as future prospects on logistics. Computers in Industry, 89, pp. 23-34.

[11] Chen, B., Wan, J., Shu, L., Li, P., Mukherjee, M. \& Yin, B. 2018. Smart factory of Industry 4.0: Key technologies, application case, and challenges. IEEE Access, 6, pp. 6505-6519.

[12] Kamilaris, A. \& Pitsillides, A. 2016. Mobile phone computing and the Internet of Things: A survey. IEEE Internet of Things Journal, 3(6), pp. 885-898.

[13] Du Plessis, J. N., Pelzer, R. \& Kleingeld, M. 2012. An automated diagnostic system to streamline DSM project maintenance. 2012 International Conference on the Industrial and Commercial Use of Energy (ICUE), pp. 7-10.

[14] Goosen, P., Swanepoel, J. A. \& du Plessis, J. N. 2016. The need for a comprehensive energy management information system for industries. South African Journal of Industrial Engineering, 27(3), pp. 1-11.

[15] Du Plessis, J. N., Prinsloo, I. M. \& Groenewald, H. J. 2013. Results from implementing a remote diagnostic and maintenance solution on energy management systems. 2013 International Conference on Industrial and Commercial Use of Energy (ICUE), pp. 35-40. 
[16] Du Plessis, J. N., Prinsloo, J. \& Vosloo, J. C. 2016. Reducing the communication costs of a remote monitoring and maintenance system for an energy services company (ESCo). SAlIE27 Proceedings, pp. 2613-1-2613-10.

[17] Prinsloo, J., Mathews, M. J., du Plessis, J. N. \& Vosloo, J. C. 2018. An information systems approach to the proactive management of subscriber identification modules in industry. SAIIE29 Proceedings, pp. 127-138.

[18] Vanganuru, K., Ferrante, S. \& Sternberg, G. 2012. System capacity and coverage of a cellular network with D2D mobile relays. Proceedings - IEEE Military Communications Conference MILCOM, pp. 1-6.

[19] Van Jaarsveld, S., van Heerden, S. W. \& van Rensburg, J. F. 2017. Development of a condition monitoring information system for deep level mines. SAlIE28 Proceedings, pp. 3422-1-3422-13.

[20] Kotze, R. L. M. \& Visser, J. K. 2012. An analysis of maintenance performance systems in the South African mining industry. South African Journal of Industrial Engineering, 23(3), pp. 13-29.

[21] du Plessis, J. N., Pelzer, R. \& Vosloo, J. C. 2015. Sustaining the performance of diverse energy management systems through reactive maintenance. 2015 International Conference on the Industrial and Commercial Use of Energy (ICUE), pp. 44-49.

[22] Rawat, P., Singh, K. D. \& Bonnin, J. M. 2016. Cognitive radio for M2M and Internet of Things: A survey. Computer Communications, 94, pp. 1-29.

[23] Al Khedher, M.A. 2011. Hybrid GPS-GSM localization of automobile tracking system. International Journal of Computer Science and Information Technology, 3(6), pp. 75-85.

[24] Farooq, U., Haq, T. ul, Amar, M., Asad, M. U. \& lqbal, A. 2010. GPS-GSM integration for enhancing public transportation management services. 2010 Second International Conference on Computer Engineering and Applications, 2, pp. 142-147.

[25] Prinsloo, J. \& Malekian, R. 2016. Accurate vehicle location system using RFID: An Internet of Things approach. Sensors, 16(6), p. 825-849.

[26] Al-Taee, M. A., Khader, O. B. \& Al-Saber, N. A. 2007. Remote monitoring of vehicle diagnostics and location using a smart box with global positioning system and general packet radio service. 2007 IEEE/ACS International Conference on Computer Systems and Applications, pp. 385-388.

[27] Zhang, R., Wang, M., Shen, X. \& Xie, L.-L. 2016. Probabilistic analysis on QoS provisioning for Internet of Things in LTE-A heterogeneous networks with partial spectrum usage. IEEE Internet of Things Journal, 3(3), pp. $354-365$.

[28] Wenwei, L., Dafang, Z., Jinmin, Y. \& Gaogang, X. 2007. On evaluating the differences of TCP and ICMP in network measurement. Computer Communications, 30(2), pp. 428-439.

[29] Gisbert, J. R., Palau, C., Uriarte, M., Prieto, G., Palazón, J. A., Esteve, M., López, O., Correas, J., LucasEstañ, M. C., Giménez, P., Moyano, A., Collantes, L., Gozálvez, J., Molina, B., Lázaro, O. \& González, A. 2014. Integrated system for control and monitoring industrial wireless networks for labor risk prevention. Journal of Network and Computer Applications, 39(1), pp. 233-252.

[30] Civerchia, F., Bocchino, S., Salvadori, C., Rossi, E., Maggiani, L. \& Petracca, M. 2017. Industrial Internet of Things monitoring solution for advanced predictive maintenance applications. Journal of Industrial Information Integration, 7, pp. 4-12.

[31] Gungor, V. C. \& Hancke, G. P. 2009. Industrial wireless sensor networks: Challenges, design principles, and technical approaches. IEEE Transactions on Industrial Electronics, 56(10), pp. 4258-4265.

[32] Prinsloo, J., Mathews, M., du Plessis, J. \& Vosloo, J. 2019. Development of a software-based monitoring and information system for industrial telemetry applications. South African Journal of Industrial Engineering, 30(1), pp. 54-68.

[33] Jiang, H. \& Dovrolis, C. 2002. Passive estimation of TCP round-trip times. ACM SIGCOMM Computer Communication Review, 32(3), pp. 75-88.

[34] Sommers, J. 2004. Comparing probe- and router-based packet-loss measurement. IEEE Internet Computing, pp. 50-56.

[35] Pasztor, A. \& Veitch, D. 2001. A precision infrastructure for active probing. Proc. Passive and Active Measurements (PAM) Workshop.

[36] Gorecky, D., Schmitt, M., Loskyll, M. \& Zuhlke, D. 2014. Human-machine-interaction in the industry 4.0 era. 12 th IEEE International Conference on Industrial Informatics (INDIN), pp. 289-294.

[37] Elghazel, W., Bahi, J., Guyeux, C., Hakem, M., Medjaher, K. \& Zerhouni, N. 2015. Dependability of wireless sensor networks for industrial prognostics and health management. Computers in Industry, 68, pp. 1-15.

[38] Prathiba, B., Jaya Sankar, K. \& Sumalatha, V. 2016. Enhancing the data quality in wireless sensor networks - A review. International Conference on Automatic Control and Dynamic Optimization Techniques (ICACDOT), pp. 448454.

[39] Barnaghi, P. \& Sheth, A. 2016. On searching the Internet of Things: Requirements and challenges. IEEE Intelligent Systems, 31(6), pp. 71-75.

[40] Prinsloo, J., Vosloo, J. \& Mathews, E. 2019. Towards Industry 4.0: A roadmap for the South African heavy industry sector. South African Journal of Industrial Engineering, 30(3), pp. 174-186. 